\title{
Characteristics of Summertime Circulation Patterns for Southern Taiwan's Monsoon Rainfall from July to September
}

\author{
Ken-Chung Ko* and Yi-Shuan Tzeng \\ Department of Geography, National Kaohsiung Normal University, Kaohsiung, Taiwan
}

Received 9 April 2012, accepted 23 October 2012

\begin{abstract}
This study documents the circulation features associated with summer monsoon rainfall over southern Taiwan from July through September over the period 1974 - 2001. Four types of monsoon systems, Monsoon I, I-TC, II and II-TC, are identified based on the daily rainfall data of 4 observational stations over southern Taiwan and the daily wind direction data of Lanyu. The total rainfall amount of Monsoon I and I-TC is much greater than that for Monsoon II and II-TC because the former two have more moisture. Monsoon I is characterized by a strong southwesterly flow over southern Taiwan due to the tightening of the pressure gradient between the monsoon trough and subtropical high over the western North Pacific. The Monsoon I-TC pattern exhibits a deep monsoon trough along with an anomalous cyclone near the East China Sea; this pattern drives a large volume of moisture that causes heavy rainfall over southern Taiwan. The circulation patterns of Monsoon I and I-TC resemble the flow pattern during the Mei-Yu or "Plum Rain" season from May through mid-July. The Monsoon II pattern reveals a trough south of Taiwan and accompanied by a strong ridge north to it. The convection is located near the southern flank of the monsoon trough. The circulation pattern of Monsoon II-TC yields a deep trough south of the westward protruding subtropical ridge. Additionally, the Monsoon II-TC is less significant because of the wide variety of the TC locations. The Monsoon II and II-TC patterns are similar to the Pacific-Japan (PJ) pattern that can affect weather in the East Asian summer monsoon area.
\end{abstract}

Key words: Summer monsoon, Atmospheric circulation, Tropical cyclone

Citation: Ko, K. C. and Y. S. Tzeng, 2013: Characteristics of summertime circulation patterns for southern Taiwan's monsoon rainfall from July to September. Terr. Atmos. Ocean. Sci., 24, 107-119, doi: 10.3319/TAO.2012.10.23.01(A)

\section{INTRODUCTION}

The concept of a natural season suggested by Wang and Lin (2002), Hsu (2005), Chou et al. (2009), and Chen et al. (2011) provides a better method to define the summer season over East Asia. A natural season is defined based on the distinct weather/climate systems that hardly coincide with the four seasons based on the astronomical calendar. Figure 1 is an example of the summer season for southern Taiwan based on the rainy seasons. The daily average rainfall in Kaohsiung in Fig. 1 suggests a long summer season with two rainy periods: one in May-June and the other between July and September. Hsu (2005) shows that the East Asian summer (May to September) monsoon is characterized by zonally elongated precipitation areas. This long

\footnotetext{
* Corresponding author

E-mail:kko@nknu.edu.tw
}

summer season can be further divided into two halves due to abrupt changes (Matsumoto 1992; Wang and Lin 2002). The first half period (May to mid-July) corresponds to the Mei-Yu season with a monsoon trough extending eastward only to the Philippines and the subtropical high ridge extending westward over Taiwan and southeast China. Strong southwesterly winds are from the Indo-China Peninsula and the South China Sea all the way toward the east of Japan. This strong southwesterly area lies near the western and northern flanks of the subtropical anticyclone. The second half period is associated with a monsoon trough penetrating as far east as $150^{\circ} \mathrm{E}$ and the subtropical anticyclone shifting northward to $35^{\circ} \mathrm{N}$. Unlike the flow pattern in the Mei-Yu season, strong southeasterly wind exists from the southern flank of the subtropical anticyclone toward Japan in the second half period (Hsu 2005). Lin and Wang (2002) further introduce the concept of "fast annual cycles" which 


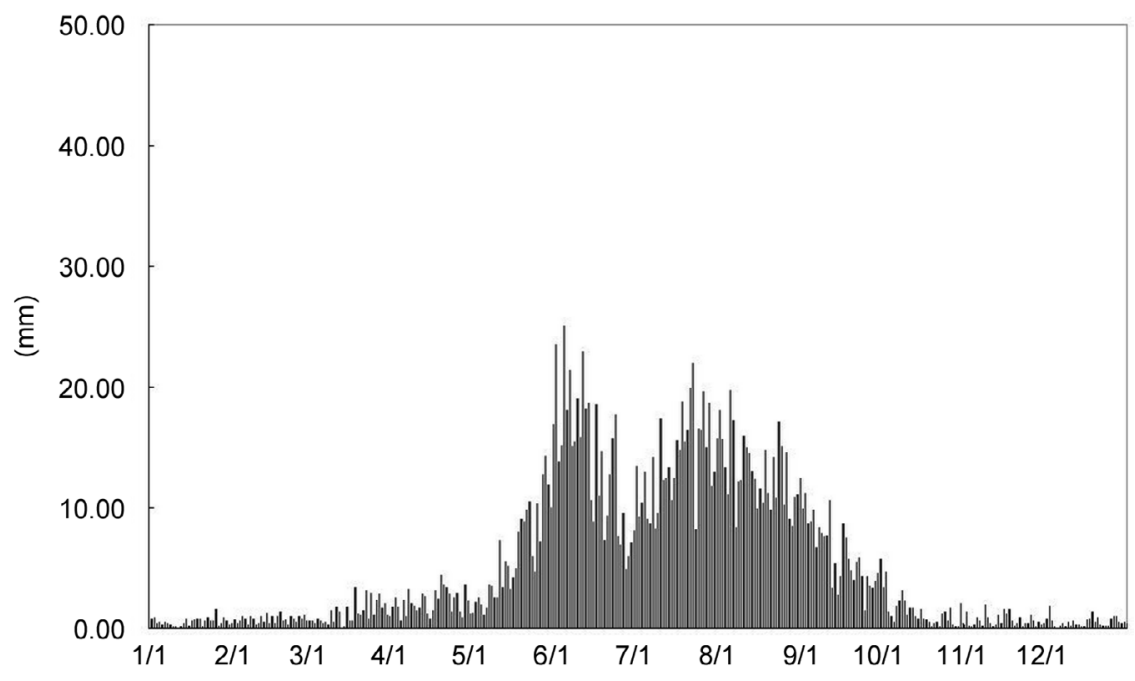

Fig. 1. The daily average rainfall (mm) in Kaohsiung over 1931 - 2006.

are composed of two major monsoon phases during the East Asian summer monsoon. The first phase spans mid-May to early July and the other from late July to early September. When the rainfall reaches its maximum in mid-June, the convergence zone becomes the Mei-Yu system near Taiwan and southern China. During the second phase, there exist numerous tropical cyclones.

One of the major large-scale circulation patterns affecting East Asian weather and climate is the Pacific-Japan (PJ) pattern (Nitta 1987). The PJ pattern is characterized by a strong convective band near the Philippines along $20^{\circ} \mathrm{N}$ and a high pressure anomaly extending from East China, through Japan Islands to the North Pacific during the summer; it may be concluded that this meridional wavy pattern could be due to Rossby waves generated by the tropical heat source associated with the intraseasonal variability and the high pressure anomalies over East Asia. Hsu and Lin (2007) find a meridionally-banded tripole rainfall pattern that resembles the PJ pattern in East Asian summer. Kosaka and Nakamura (2010) successfully simulate the PJ pattern against diabatic heating using a two-layer model. They also find that the PJ pattern can, in turn, intensify the anomalous convective activity over the Philippines.

Another pattern of wave-like disturbances moving toward the South China Sea in a shorter time scale (3 - 8 days) is also identified by Lau and Lau (1990) and Chang et al. (1996). Lau and Lau (1990) perform the lag-correlation method on the tropical disturbances with synoptic time scales and find northwestward propagating waves in the western North Pacific during June - August. They also claim that these synoptic disturbances prevail predominantly when the subtropical anticyclone protrudes westward to eastern China. Chang et al. (1996) further examine these synoptic waves and find that most of these waves are associated with tropical cyclones. They also discover the role of the subtropical high in preventing the synoptic disturbances from propagating further north.

The present study will examine the circulation systems associated with the monsoon rainfall during the second half of the long summer season (July - September) over southern Taiwan. Unlike the circulation systems dominated mostly by the Mei-Yu frontal systems in the first cycle (May - June), the second cycle is controlled by the monsoon trough and TCs (Hsu 2005; Ko and Hsu 2009). The objectives of this study are (1) to define the summer monsoon rainfall types over southern Taiwan, and (2) to document the circulation features associated with different summer monsoon rainfall types. Section 2 describes the data and analysis procedures regarding the definition of summer monsoon rainfall types. Section 3 depicts the composites of the circulation systems associated with different summer monsoon rainfall types and section 4 illustrates the studies of special cases. Concluding remarks are presented in section 5 .

\section{DATA AND ANALYSIS PROCEDURES}

The circulation data used in this study were extracted from the European Centre for Medium-range Weather Forecast (ECMWF) re-analysis (ERA40, Uppala et al. 2005). The ERA40 contains 6-hourly $(0000,0600,1200$ and 1800 UTC) temperature, humidity, horizontal winds, pressure vertical velocity, and geopotential on a $2.5^{\circ} \times 2.5^{\circ}$ latitudelongitude grid. The best-track tropical cyclone data were obtained from the Joint Typhoon Warning Center (JTWC) at Guam. We analyzed the 28-year data during July - September (JAS) in 1974 - 2001. The interpolated outgoing longwave radiation (OLR) data are provided daily by the Climate Diagnostics Center/National Oceanic and Atmospheric 
Administration with the same grid spacing as the ECMWF analysis. The minimum areas of OLR usually stand for strong convection.

The daily precipitation data from four of the Central Weather Bureau's (CWB) observation stations (Kaohsiung, Tainan, Chiayi, and Hengchun) are included for case selection. The CWB is known to have a complete and good-quality set of observational data; the locations of these 4 stations are mostly near the southwestern portion of Taiwan. This area is known for facing the southwesterly flow in summer (Hsu 2005). In order to separate the monsoon flow patterns, the wind direction and speed data of Lanyu were taken into account for the aforementioned 28 years over July, August, and September (JAS). Figure 2 illustrates the positions of these 5 stations. The reason for choosing Lanyu's wind data is that the wind of this station best represents the large-scale circulation because it is on a small island near the southeastern coast of Taiwan and is neither in a city nor near the mountains. The location of Lanyu is close to southern Taiwan and will exclude the urban and topographic effects that might have some effect on the other 4 stations. Figure 3 shows that the Lanyu wind directions are in good agreement with the flow patterns generated from the global analysis for two examples (one is southwesterly and the other is easterly) and therefore Lanyu is appropriate for representing the large-scale wind. The Lanyu surface wind roses (Fig. 4) show southwesterly prevailing wind direction in July (Fig. 4a) and August (Fig. 4b), and a secondary prevailing wind direction to be northeasterly. Although the dominant wind direction in September (Fig. 4c) is northeasterly due to the enhancement of the northeasterly monsoon, a secondary wind direction-southwesterly exists. The wind roses indicate that during the latter half of the East Asian summer monsoon season, southwesterly and northeasterly are two major largescale prevailing wind directions near southern Taiwan.

The rainy days for each station during July to September are divided into 3 categories based on the station data: typhoon, Monsoon I, and II. A typhoon rainy day is defined when there is measurable rainfall $(\geqq 0.1 \mathrm{~mm})$ at any of those 4 stations and at least one typhoon entering the box of 18 $28^{\circ} \mathrm{N}, 117-125^{\circ} \mathrm{E}$ (Fig. 5). The box is the same as in Chen and Fan (2003) and is used for issuing typhoon warnings by the CWB. The monsoon rainy days are further divided into Monsoon I and II types which are based on the daily prevailing wind directions of Lanyu. A Monsoon I rainy day is defined as the day with precipitation and prevailing southwesterly wind (wind direction greater than $135^{\circ}$ less than $315^{\circ}$ as in Fig. 5). On the other hand, a Monsoon II

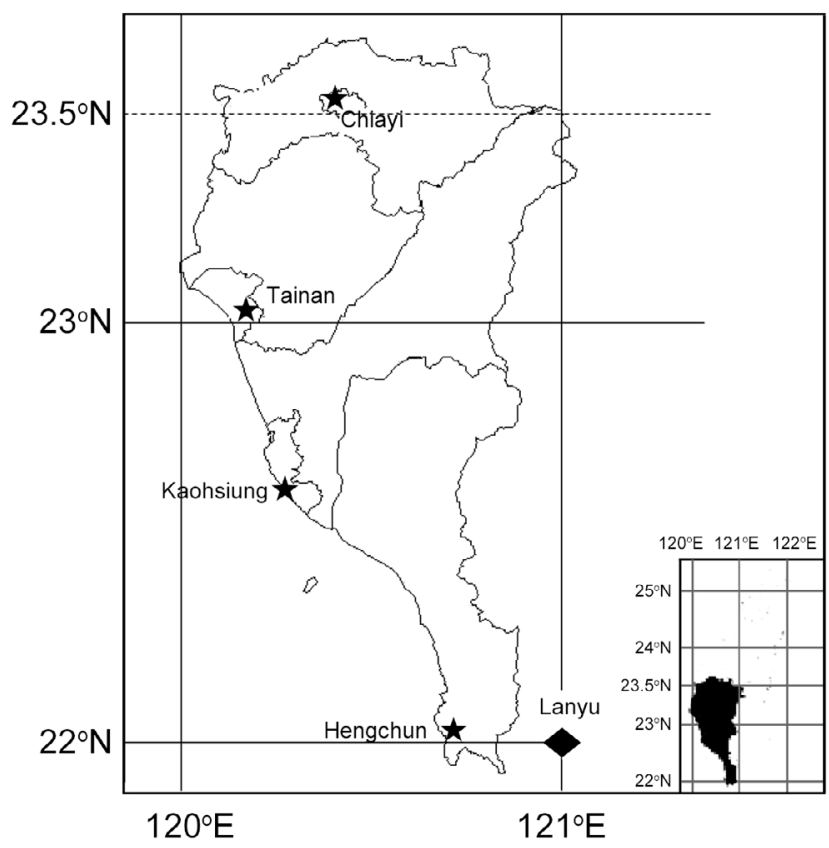

Fig. 2. Locations of $5 \mathrm{CWB}$ stations. Those stations for rainfall are marked by stars and Lanyu for wind data is marked by a diamond. The small map in the lower right hand corner represents the map of Taiwan and the black area is the southwestern Taiwan area where the blow-up map is in the left hand side. (a)

$1982 / 07 / 05$

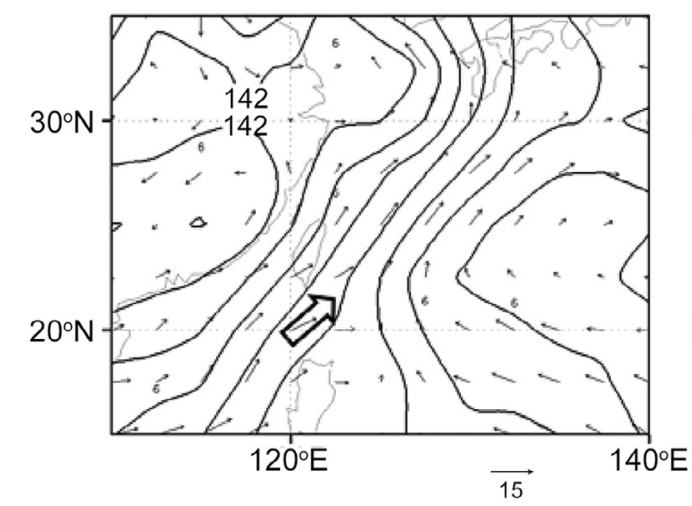

(b) $1978 / 09 / 24$

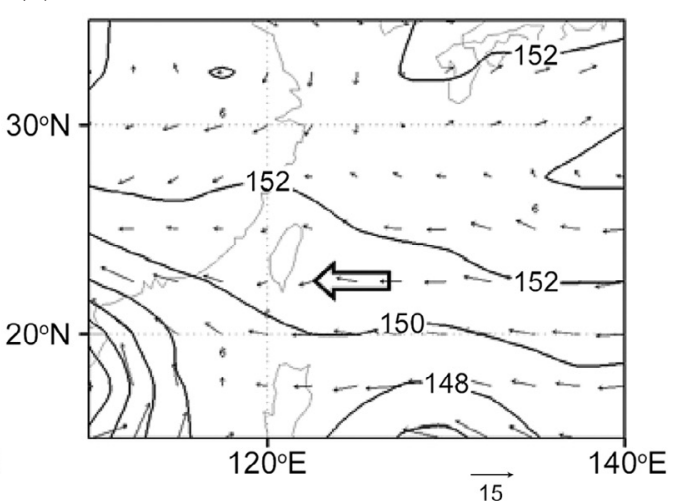

Fig. 3. Circulation patterns of $850 \mathrm{hPa}$ geopotential and wind vectors for (a) a southwesterly case, and (b) an easterly case. The interval for geopotential is $1(\times 100) \mathrm{m}^{2} \mathrm{~s}^{-1}$. The open arrows represent the corresponding wind directions of Lanyu station. 
(a) July

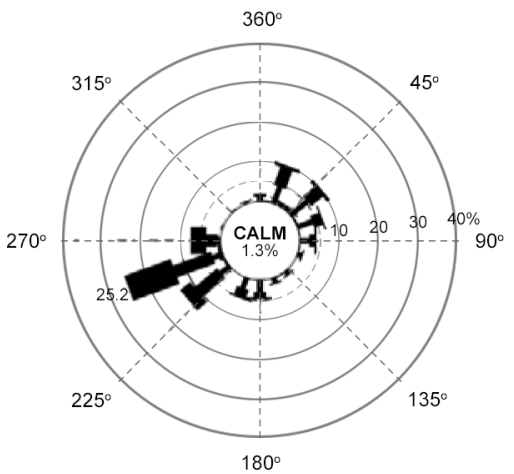

(b) August

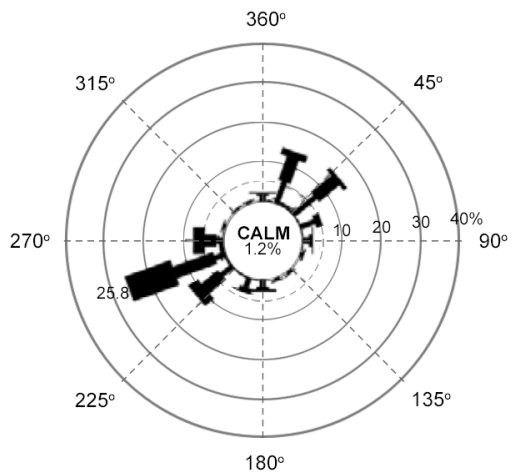

(c) September

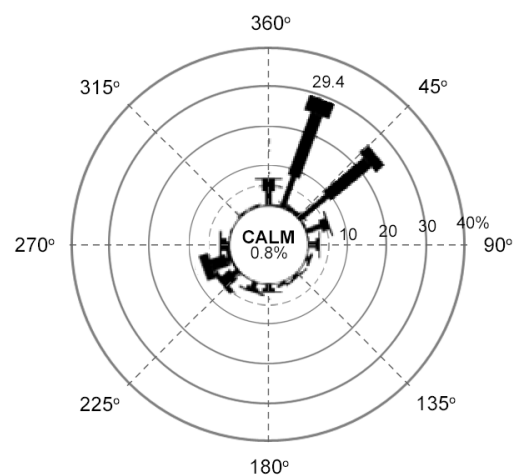

Fig. 4. Twenty-eight year (1974 - 2001) averaged wind roses of Lanyu for (a) July, (b) August, and (c) September. The word "CALM" and the percentage in the center of the wind roses represent the percentages of hours when the wind speed is zero.

rainy day is defined as the day with precipitation and prevailing northeasterly wind (wind direction greater than $315^{\circ}$ and less than $135^{\circ}$ as in Fig. 5). The reason for defining Monsoon II rainy days is to examine the summer monsoon type with prevailing wind other than the southwesterlies. As in Fig. 4, the northeasterly wind also plays an important role during the July-September season. According to Hsu (2005), strong easterly or southeasterly flow from the southern flank of the subtropical high tends to penetrate into this area.

Cases for typhoon, Monsoon I and II are selected for further circulation studies. The typhoon cases are chosen if any of those 4 stations contains at least one typhoon rainy day. A Monsoon I case contains at least 3 consecutive Monsoon I rainy days for at least half of the 4 stations. These 4 stations and 3 (at least) consecutive days will create 12 day panels. Among these panels, half of the total panels must meet the Monsoon I rainy day criteria and the rainy days with precipitation hours between noon and $6 \mathrm{pm}$ must not exceed $1 / 2$ of the total rainy days. The reason for the latter criterion is to exclude the influence of the afternoon shower due to local heating. If the case lasts more than 3 days, the same ratio of total panels will apply to the case selection criteria. Table 1 shows an example of a Monsoon I case in 1976. As seen from Table 1, there exist days that fail to satisfy Monsoon I rainy day criteria. However, most of the day panels still satisfy the criteria. The case selection criteria for Monsoon II cases are similar to those as for Monsoon I cases except that they have to meet the Monsoon II rainy day criteria. An example of a Monsoon II case in 1979 is shown in Table 2. Although only one station satisfies the criteria on the first day, most of the following days still reveal a clear Monsoon II case. In order to examine the tropical cyclones' (TCs') influence on the monsoon rainfall, two more categories are separated from Monsoon I and II, namely Monsoon I-TC and II-TC. These two monsoon cases are defined if any TC appears outside the box for the aforementioned ty-

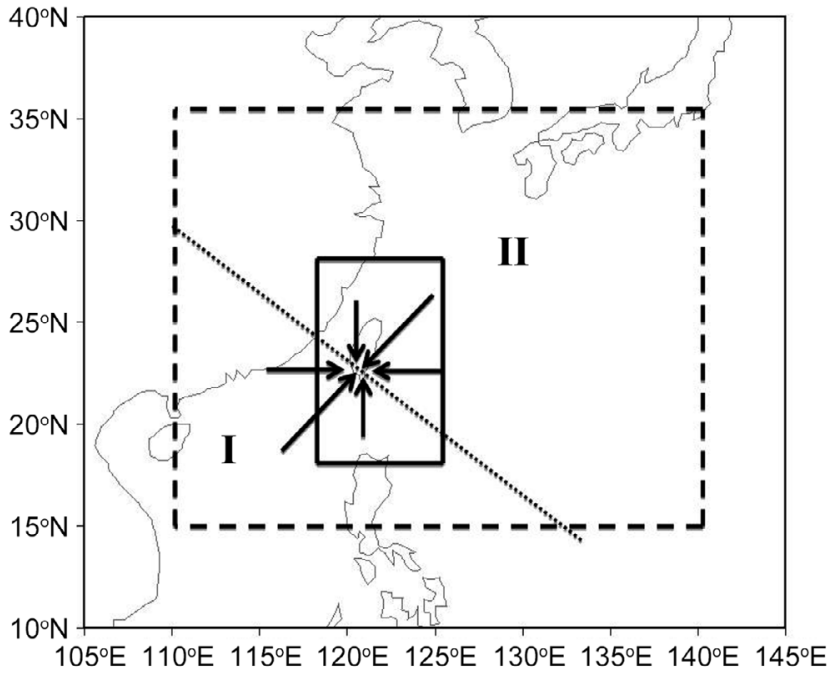

Fig. 5. Schematic diagram illustrating the wind directions of Monsoon I and II. The inner box (solid) surrounding Taiwan represents the area for defining the typhoon rainfall. The outer box (dashed-line) represents the area defining Monsoon I-TC and Monsoon II-TC cases when a typhoon occurs outside the inner box and inside the outer box.

phoon rain but inside the outer box $\left(15-35^{\circ} \mathrm{N}, 110-140^{\circ} \mathrm{E}\right)$ as in Fig. 5. These two more categories are selected to include cases such as the rainy days induced by the southwesterly flow after the typhoon passage. The resulting numbers of cases for Monsoon I, I-TC, II and II-TC are 52, 27, 40 and 15 respectively (Table 3 ). Among these four monsoon categories, the number of Monsoon I cases and total days are about twice of that for Monsoon I-TC, but the daily average precipitation of Monsoon I-TC is stronger than that for Monsoon I. Likewise, the number of Monsoon II cases and total days are about three times as those for Monsoon II-TC, but the daily average precipitation of Monsoon II is only about a quarter of that for Monsoon II-TC. This implies the strong influence of the TCs in enhancing the convection as well as the rainfall to southern Taiwan. Overall, the 
Table 1. Example of a Monsoon I case.

\begin{tabular}{l|l|cccccc}
\hline \multicolumn{2}{c|}{$\mathbf{1 9 7 6}$} & $\mathbf{7 / 1}$ & $\mathbf{7 / 2}$ & $\mathbf{7 / 3}$ & $\mathbf{7 / 4}$ & $\mathbf{7 / 5}$ & $\mathbf{7 / 6}$ \\
\hline Lanyu & Wind direction $\left(^{\circ}\right)$ & 270 & 270 & 270 & 270 & 247.5 & 270 \\
Tainan & Rainfall $(\mathbf{m m})$ & 1.8 & 20.1 & 38.8 & 213 & 80.9 & 66.8 \\
Kaohsiung & Rainfall $(\mathbf{m m})$ & 0 & 0.5 & 26.5 & 101 & 61.5 & 144 \\
Chiayi & Rainfall (mm) & 4.4 & 27.6 & 58.3 & 102.7 & 73.5 & 33.3 \\
Hengchun & Rainfall (mm) & 3 & 3.3 & 3.4 & 12.2 & 36 & 67.7 \\
\hline
\end{tabular}

Table 2. Example of a Monsoon II case.

\begin{tabular}{l|l|cccc}
\hline \multicolumn{2}{l|}{1979} & $\mathbf{7 / 7}$ & $\mathbf{7 / 8}$ & $\mathbf{7 / 9}$ & $\mathbf{7 / 1 0}$ \\
\hline Lanyu & Wind direction $\left(^{\circ}\right)$ & 22.5 & 337.5 & 22.5 & 22.5 \\
Tainan & Rainfall $(\mathbf{m m})$ & 4.1 & 0 & 1.1 & 0.5 \\
Kaohsiung & Rainfall $(\mathbf{m m})$ & 0.5 & 1.6 & 11.7 & 4.9 \\
Chiayi & Rainfall $(\mathbf{m m})$ & 2.5 & 0 & 68.8 & 61.6 \\
Hengchun & Rainfall $(\mathbf{m m})$ & 0 & 0.5 & 61.9 & 23.9 \\
\hline
\end{tabular}

Table 3. Statistics for Monsoon I and II.

\begin{tabular}{l|cccc}
\hline & Monsoon I & Monsoon I-TC & Monsoon II & Monsoon II-TC \\
\hline Number of cases & 52 & 27 & 40 & 15 \\
Total days & 292 & 128 & 182 & 66 \\
Days/case & 5.61 & 4.74 & 4.55 & 4.4 \\
Total precipitation (4 stations) (mm) & 25189.6 & 14011.2 & 4284.7 & 6360.4 \\
Daily average rainfall (mm) & 21.57 & 27.37 & 5.89 & 24.09 \\
\hline
\end{tabular}

precipitation rate is stronger for Monsoon I and I-TC. The percentage of precipitation for each type of rainfall, which is calculated by dividing the precipitation of each type by the total precipitation of those 4 stations, is shown in Fig. 6. Typhoons account for nearly half of the total precipitation $(47.76 \%)$. Those two Monsoon I cases explain about $1 / 3(35.39 \%)$ which is much greater than that for those two Monsoon II cases $(5.74 \%)$. The reason for this difference could be attributed to heavier rainfall and longer duration for Monsoon I and I-TC cases (Table 3). The precipitation that fails to fall into those categories (typhoon and 4 monsoon types) will be classified as "other" in Fig. 6. Since the present study focuses only on the monsoon rainfall and the associated large-scale circulation, the following discussion will be mainly on Monsoon I, I-TC, II and II-TC.

The selected cases are further composited for these 4 monsoon categories. The middle time (1200 UTC in the middle day) of each case is defined as Day0. The level of $850 \mathrm{hPa}$ is chosen for the large-scale circulation patterns because this level stands for typical lower tropospheric flow patterns with less influence from the boundary layer. The results of the composite circulation patterns are discussed and shown in the following section.

\section{CIRCULATION FEATURES AND MOISTURE SUPPLY}

The large-scale composite wind fields along with geopotential at $850 \mathrm{hPa}$ and OLR in the middle of the composite period (Day0) associated with Monsoon I, I-TC, II, and II-TC are shown in Fig. 7. At Day0 of Monsoon I, a strong southwesterly flow existed from the Bay of Bengal through the South China Sea, over Taiwan to southern Japan. A weak trough is located over southwestern China and the subtropical ridge extends southwestward to the Philippines. The tightening of the pressure gradients due to this trough/ ridge system enhances the southwesterly flow. A significant convection axis in southern China extends eastward to Taiwan which is near the central portion of the southwesterly flow. This convection axis develops and moves northeastward along the background flow (not shown). However, the circulation pattern of Monsoon I-TC exhibits a deeper 
trough from southwestern to eastern China and merges with a closed cyclonic circulation over the East China Sea. Although the deepening may not be due solely to TCs, the expansion and deepening of the monsoon trough tend to move the southwesterly belt off the east coast of China so the edge of the strong wind sweeps through southern Taiwan. The convection associated with the Monsoon I-TC southwesterly flow seems to be stronger and more significant than that

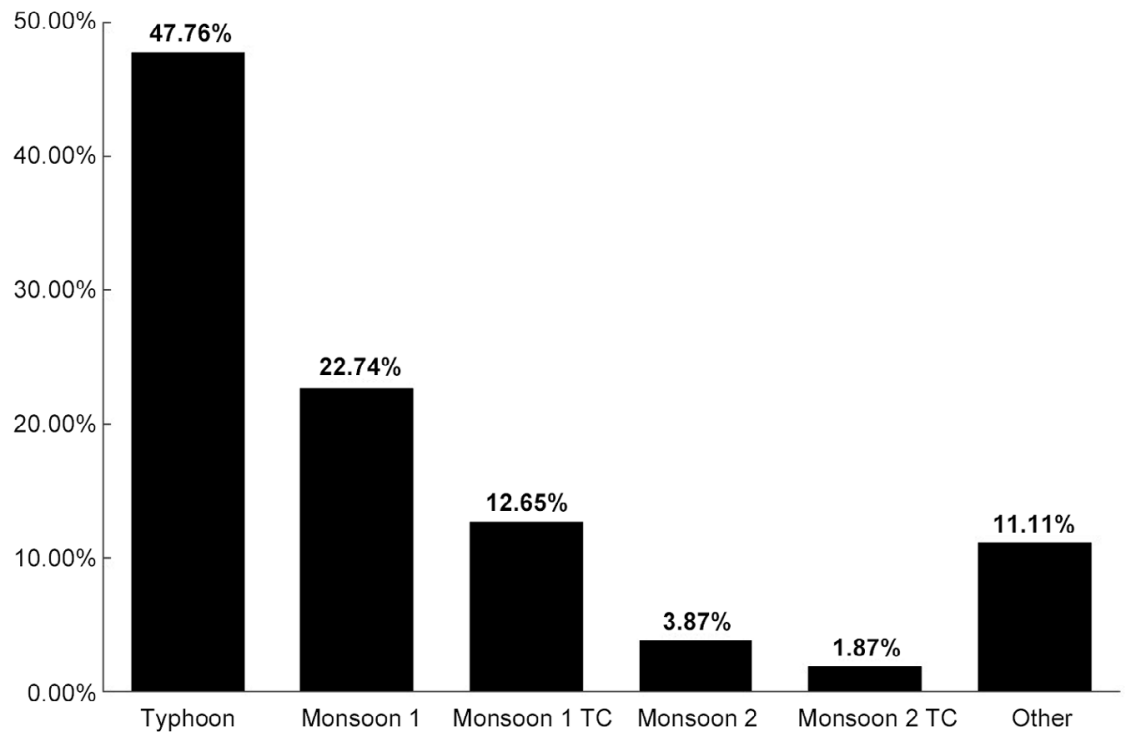

Fig. 6. Percentages of rainfall types in southern Taiwan from July to September.

(a)

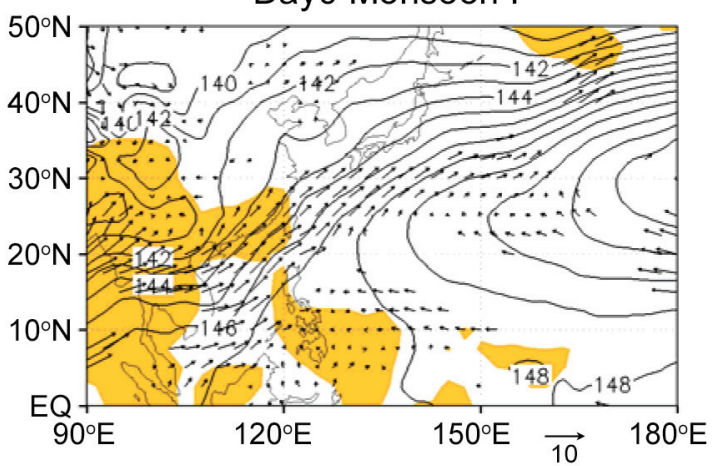

(c)

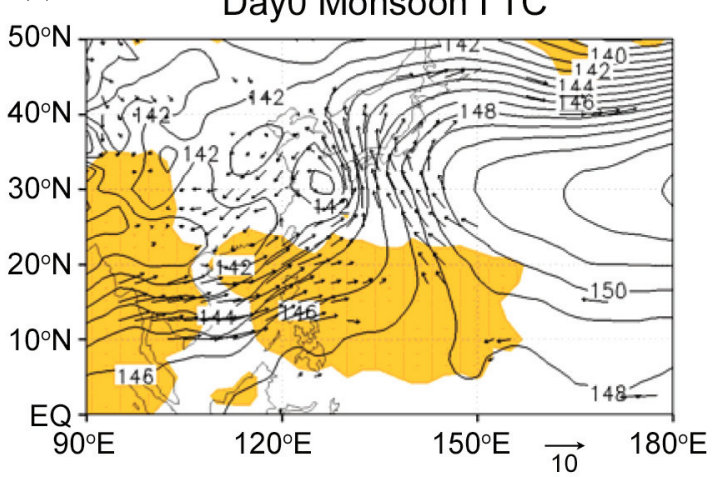

(b) Day0 Monsoon II

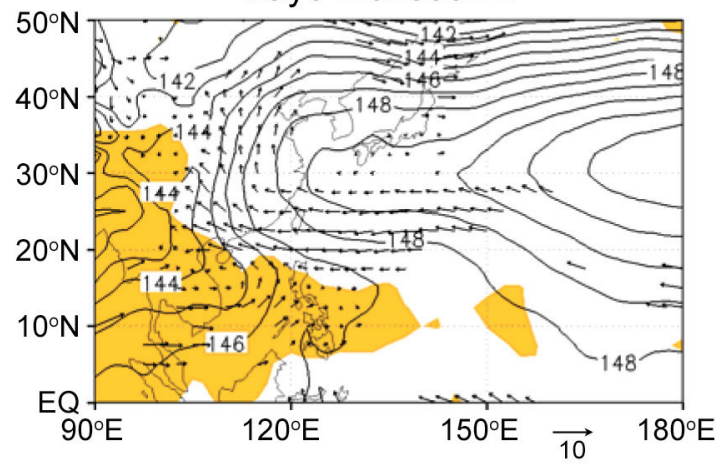

(d)

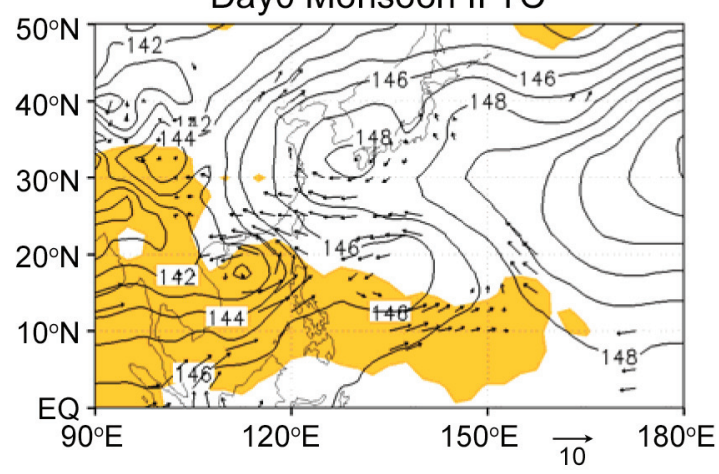

Fig. 7. Composite maps of OLR and $850 \mathrm{hPa}$ geopotential and wind vectors at Day0 for Monsoon I and II [(a) and (b)]. Also shown are the maps for Monsoon I-TC and II-TC [(c) and (d)]. The unit for OLR is $\mathrm{W} \mathrm{m}^{-2}$ and only areas smaller than $220 \mathrm{~W} \mathrm{~m}^{-2}$ are shaded and shown. The interval for geopotential is $1(\times 100) \mathrm{m}^{2} \mathrm{~s}^{-1}$ and only wind vectors exceeding the $95 \%$ confidence level are shown. 
for Monsoon I. Overall, the circulation patterns of Monsoon I and I-TC resemble the large-scale Mei-Yu-like pattern as in Lin and Wang (2002) and Hsu (2005).

Unlike the Monsoon I and I-TC circulation patterns, Monsoon II yields a weak trough over the South China Sea along with a convective area extending eastward to $10^{\circ} \mathrm{N}$, $155^{\circ} \mathrm{E}$. Additionally, a strong ridge to the north of Taiwan stretching westward from the subtropical high is accompanied by a strong southeasterly flow to the northeast of the convection. Although less significant compared to Monsoon II, the Monsoon II-TC flow pattern exhibits a weaker ridge north to Taiwan and stronger convection near the South China Sea. This wavy meridional structure as in Monsoon II and II-TC resembles the PJ pattern in Nitta (1987). The PJ pattern is characterized by a strong convection from the Philippines to western Pacific around $20^{\circ} \mathrm{N}$, and a high pressure ridge from East China, through Japan to North Pacific during the northern summer.

Another interesting point of the Monsoon II and IITC pattern is the confined convection located south of the monsoon trough. This phase difference is similar to that as in Hsu and Weng (2001) in the northward propagating intraseasonal oscillation and in a model simulation by tropical heating as in Hoskins and Karoly (1981). Kosaka and Nakamura (2010) simulate the PJ pattern initiated by tropical heating and found a similar phase relationship between the convection and circulation. They further investigate the relationship and found the PJ pattern can also feedback and enhance the tropical convection.

Figure 8 displays the $850 \mathrm{hPa}$ moisture fluxes for those four monsoon types. Apparently, the moisture source is from the Bay of Bengal through the South China Sea, Taiwan to Japan in Monsoon I. Although the moisture convergence is weak, the Monsoon I moisture supply appears to be uninterrupted from lower latitudes to Taiwan. The Monsoon I-TC pattern shows a slightly different feature. Instead of supporting the moisture along the East Asian coast, the big cyclonic circulation in Monsoon I-TC as in Fig. 7 creates a confluent zone from the East China Sea southeastward to $5^{\circ} \mathrm{N}, 160^{\circ} \mathrm{E}$. This confluent zone is located near the area (a)

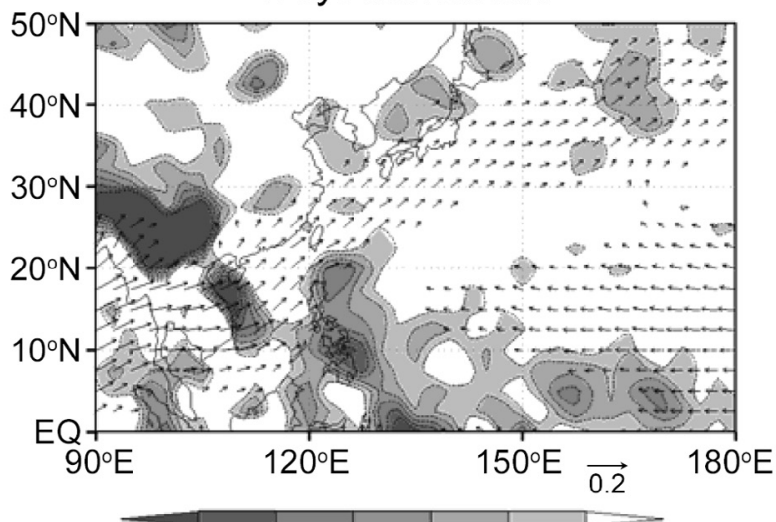

$-6 e-08-5 e-08-4 e-08$-3e-08 -2e-08 -1e-08

(c)

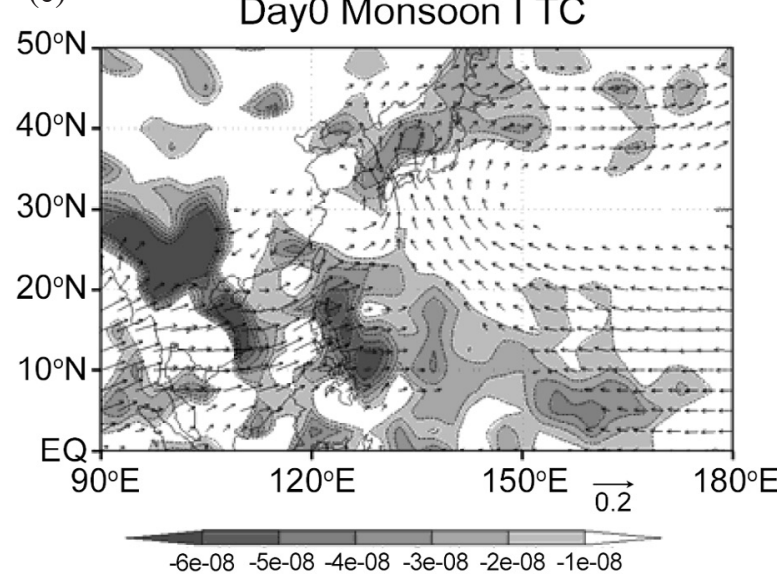

(b)

Day0 Monsoon II

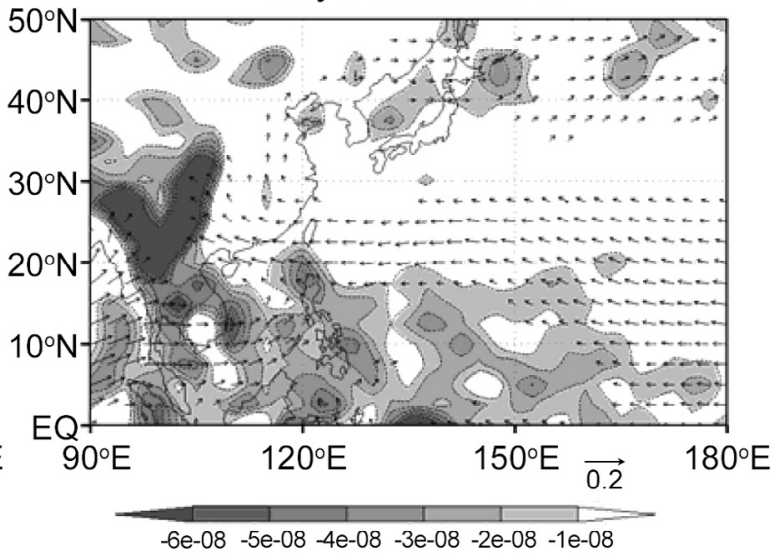

(d)

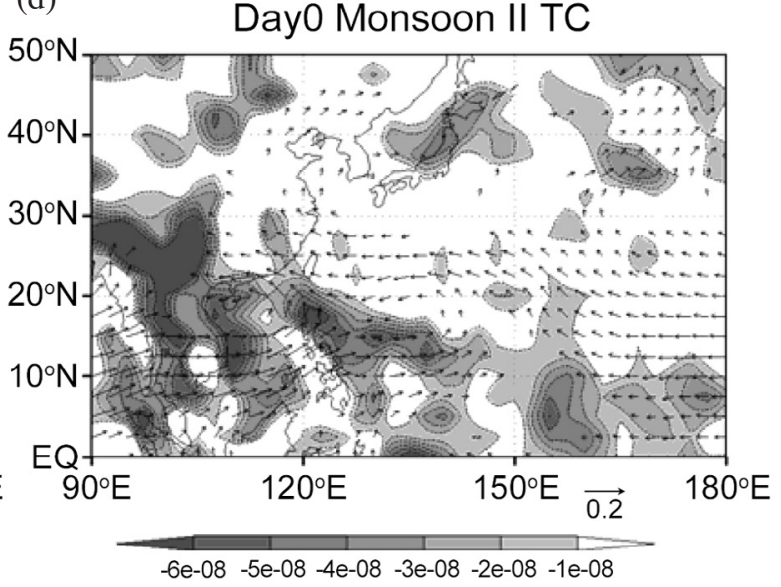

Fig. 8. Composite maps of $850 \mathrm{hPa}$ moisture fluxes (vectors) and moisture flux convergence (shading, in $\mathrm{g} \mathrm{kg}^{-1} \mathrm{~s}^{-1}$ ) at Day0 for Monsoon I and II [(a) and (b)]. Also shown are the maps for Monsoon I-TC and II-TC [(c) and (d)]. The vectors smaller than $0.015 \mathrm{mg} \mathrm{kg}^{-1} \mathrm{~s}^{-1} \mathrm{are}$ omitted. 
where the southwesterly monsoon flow and the southeasterly flow around the southern subtropical high, merge together. Therefore the confluent zone is also responsible for strong moisture convergence near southern Taiwan. However, Monsoon II and II-TC exhibit most of the moisture fluxes near the southern flank of the subtropical high and the moisture convergence is confined to the outer rim of the subtropical ridge. The patterns for Monsoon II and II-TC are similar except the moisture convergence is stronger in Monsoon II-TC.

In order to uncover circulation features hidden behind the climatological mean field, the climatological mean fields for the wind, geopotential, and OLR are calculated and subtracted from the composite fields. The $850 \mathrm{hPa}$ geopotential anomalies of Monsoon I as in Fig. 9 show that an anomalous anticyclone slightly expands along the latitudinal band around $15^{\circ} \mathrm{N}$ from 120 to $170^{\circ} \mathrm{E}$. This anomalous anticyclone is responsible for enhancing the southwesterly flow and the convective anomalies from the northern South China Sea to southern Japan. The geopotential of Monsoon I-TC, on the other hand, yields a large anomalous cyclone centered near the East China Sea and a secondary trough extending along the southeastern coast of China. An anomalous anticyclone is located northeast to the anomalous cyclone and enhances the southeasterlies emerging between these two systems due to the tightening of the pressure gradients. Therefore, the anomalous cyclone along with the trough is responsible for generating the southwesterly and the convective anomalies. Between the anomalous southwesterly and southeasterly flow is the confluent zone as discussed earlier in Fig. 7. These features of Monsoon I-TC are different from that as in Monsoon I. Also shown in the Monsoon I-TC map are the TC positions accompanying the composite cases. The TCs tend to occur near the confluent zone and the southern flank of the trough. Thus, for Monsoon I-TC, the large cyclonic anomaly and the trough create favorable regions for the southwesterly flow to supply moisture and help TCs to form and develop. The Monsoon I anomalies, however, are not as favorable as that in Monsoon I-TC.

The Monsoon II and II-TC circulation anomalies, however, exhibit totally different patterns compared to that as in Monsoon I and I-TC. Most of the eastern China, Korea, Japan and Taiwan are occupied by an anomalous anticyclone for Monsoon II (Fig. 9). A weak trough is located over Vietnam and the northern South China Sea and the anomalous convection is confined over these areas. In the Monsoon II-TC phase, the pattern resembles the one as in Monsoon II except for a weaker anomalous anticyclone and stronger trough and convection. A close look at the TC positions associated with those Monsoon II-TC cases reveals a more (a)

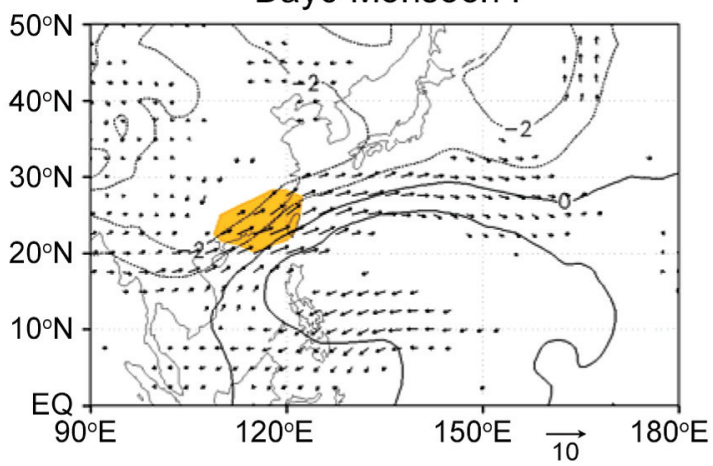

(c)

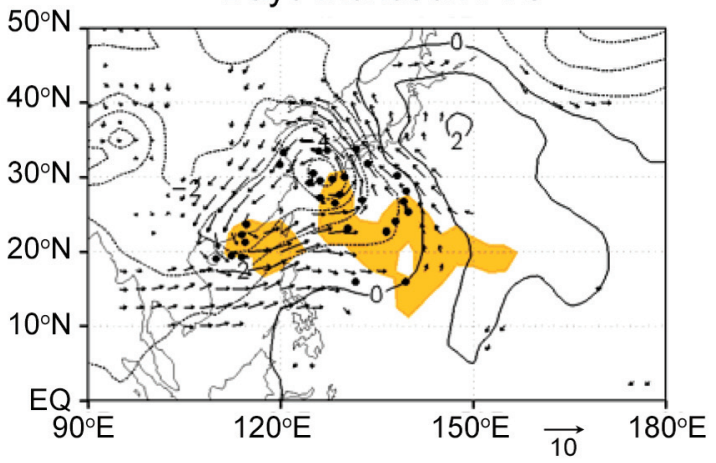

(b)

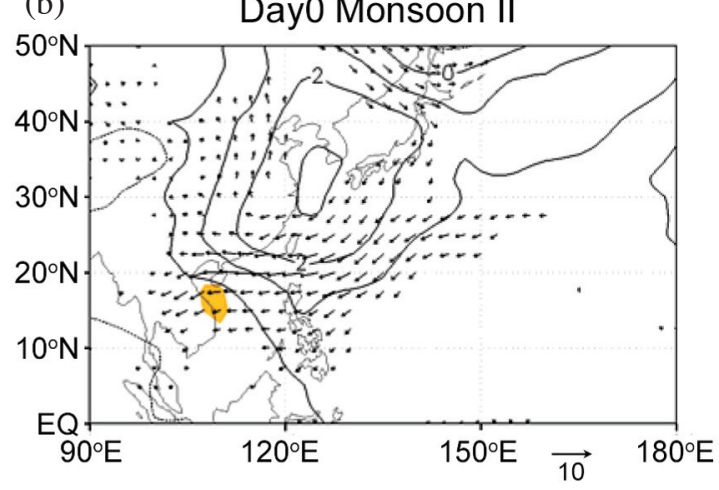

(d)

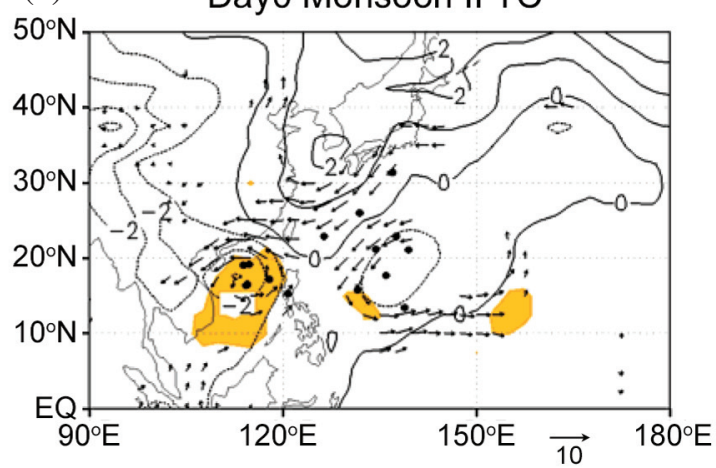

Fig. 9. Composite anomalies of OLR and $850 \mathrm{hPa}$ geopotential and wind vectors at Day0 for Monsoon I and II [(a) and (b)]. Also shown are the maps for Monsoon I-TC and II-TC [(c) and (d)] and the corresponding TC positions (dots). The unit for OLR is W $\mathrm{m}^{-2}$ and only areas smaller than -10 W $\mathrm{m}^{-2}$ are shaded and shown. The interval for geopotential is $1(\times 100) \mathrm{m}^{2} \mathrm{~s}^{-1}$; only wind vectors exceeding the $95 \%$ confidence level are shown. 
scattered distribution of TCs, although some of them seem to be clustered over the northern South China Sea. Since there are fewer cases in Monsoon II-TC, the pattern might explain why fewer wind vectors and convective areas exceeding the $95 \%$ confidence level. In other words, Monsoon II-TC can be less stable compared to the other 3 monsoon patterns.

The meridional dipole pattern as in Figs. $9 \mathrm{~b}$ and d resembles the PJ pattern as in Nitta (1987). Kosaka and Nakamura (2010) performed a series of model experiments and their results show that the diabatic heating near $20^{\circ} \mathrm{N}$ and situated in an asymmetric background flow with a monsoon trough to the west and an anticyclone to the east can generate a PJ-like meridional pattern. It is thus suggested that the circulation patterns of Monsoon II and II-TC could be attributed to the PJ pattern generated by tropical heating.

In order to further examine the relationship between the PJ pattern and the above monsoon types, a modified PacificJapan index (PJI) similar to Choi et al. (2010) is adopted and the formula is as follows:

$\mathrm{PJI}=\mathrm{Z}_{850}\left(30^{\circ} \mathrm{N}, 130^{\circ} \mathrm{E}\right)-\mathrm{Z}_{850}\left(15^{\circ} \mathrm{N}, 120^{\circ} \mathrm{E}\right)$

where $Z_{850}$ represents the $850 \mathrm{hPa}$ geopotential. The grid points (Table 4) are further west compared to that reported by Choi et al. (2010) because we choose these two points for the index so southern Taiwan is located near the center of these two points. The averaged PJI is calculated at Day0 over all cases for Monsoon I (52) and I-TC (27), and for Monsoon II (40) and II-TC (15). It turns out that these two PJIs (Table 4) yield values of opposite signs indicating different large-scale circulation patterns. Monsoon II and II-TC have a positive value of PJI which means their patterns are in good agreement with the PJ pattern. However, Monsoon I and I-TC show the opposite sign of the PJ pattern. The results indicate that during July-September seasons, these two types of monsoon circulations occur alternately and bring rainfall to southern Taiwan.

\section{CASE STUDIES}

Figure 10 shows the typical cases for those four types of monsoon patterns, in which the structure of the circulation characteristics best represents the composite results. The Monsoon I typical case (Fig. 10a) displays a strong southwesterly flow from the South China Sea through Taiwan to southern Japan. Apparently the enhancement is caused not only by tightening the pressure gradient but also by merging the wind maximum from the southern flank of the subtropical high to the southwesterly. Thus by enhancing the southwesterly flow, this monsoon pattern opens a pathway for the supply of moisture. For the typical case of Monsoon I-TC (Fig. 10c), an intense cyclone is centered near south- ern Korea and is accompanied by a strong southwesterly tail extending through southern Taiwan to the northern South China Sea. This case represents a recurving TC transforming into an extratropical cyclone. In addition, this kind of recurving TC usually brings much precipitation to southern Taiwan within a few days after its passage through Taiwan. According to Holland (1995), this kind of TCs is less understood and can possibly bring more damage to this area. Ko and Hsu (2006) also find that the recurving TCs are usually associated with periodic oscillations that propagate to the Taiwan-Japan area approximately every two weeks.

The typical Monsoon II case (Fig. 10b) exhibits a solid subtropical high protruding westward to central China and southern Taiwan experiences a southeasterly flow. The subtropical high acts as a blocking anticyclone so the weather system affecting southern Taiwan could only come from the southwestern flank of the subtropical high moving northwestward. This kind of weather systems usually brings less precipitation due to the mountain effect. The Central Mountain Range of Taiwan is located east of those 4 stations in southern Taiwan and this mountain would block the moisture supply. Therefore Monsoon II precipitation rate is weak. However, the TCs generally propagate westward/ northwestward during the Monsoon II-TC phase (Fig. 10d). When the TC moves to the northern South China Sea, the circulation around the TC drives the southeasterly flow to southern Taiwan along with the convection.

Since the TCs usually form and develop in random ways and might affect the significance of the composite results, two special cases each for Monsoon I-TC and II-TC are selected and the maps are in Fig. 11. For Monsoon I-TC (Figs. 11a and b), each case exhibits two TCs in the East Asian monsoon region. Although one of the TCs is located southwest to Taiwan as seen in Fig. 11a, the southwesterly/ southerly flow associated with it still affects the south of Taiwan. The other TC in Fig. 11a is located near southern Japan, which is far from Taiwan and can only nominally influence the area that the present study focuses on. Similarly there exists a TC near the northern South China Sea in Fig. 11b, but another TC, which was in the East China Sea, reveals a much stronger structure. These two TCs are combined together and generate much stronger southwesterly flow to southern Taiwan. Therefore, the circulation pattern of Monsoon I-TC may not be caused solely by the recurving TCs. Instead, an intense TC located southwest to Taiwan can also contribute to the Monsoon I-TC pattern.

The circulation anomalies associated with TCs in Monsoon II-TC raise a question: how can the TCs far away to the east of Taiwan affect the weather in southern Taiwan. The special cases for Monsoon II-TC (Figs. 11c and d) may answer this question. In Fig. 11c, there are two TCs in this area, one is in the South China Sea and the other centered near $20^{\circ} \mathrm{N}, 135^{\circ} \mathrm{E}$. Apparently southern Taiwan is influenced by the former and the latter only plays a secondary 
role in affecting Taiwan. However, there is only one TC in Fig. $11 \mathrm{~d}$, which is located near $25^{\circ} \mathrm{N}, 132^{\circ} \mathrm{E}$. Although located $1000 \mathrm{~km}$ away to the east of Taiwan, this intense TC in Fig. $11 \mathrm{~d}$ creates strong northeasterly flow which may generate convergence near southern Taiwan. Thus these special cases may explain why Monsoon II-TC is less significant.

\section{SUMMARY AND DISCUSSION}

The East Asian summer monsoon rainfall during July to September is divided into four types, namely Monsoon I, I-TC, II and II-TC, based on the daily rainfall data of 4 observation stations over southern Taiwan, the daily wind direction data of Lanyu and the TC data. Monsoon I rainy days are classified basically by a significant prevailing southwesterly wind and Monsoon II rainy days are chosen by mostly a prevailing easterly wind. Monsoon I-TC and II-TC follow the criteria for Monsoon I and II, respectively, except for the existence of TCs other than the area surrounding Taiwan. The amount of precipitation for Monsoon I and I-TC accounts for $35.39 \%$ which is much greater than that for Monsoon II and II-TC (5.76\%) of the total precipitation of those 4 stations. Part of the reason for this difference is attributed to heavier rainfall and longer duration caused by the Monsoon I and I-TC circulations.

To summarize the aforementioned results, schematic diagrams are shown in Fig. 12. The circulation pattern associated with Monsoon I reveals that a monsoon trough is located over southern China and the subtropical ridge extending southwestward to the Philippines. This trough/ridge system seems to induce the southwesterly and supply moisture to the area near Taiwan through tightening the pres-

Table 4. The latitude/longitude for PJ index and the averaged PJ indices for Monsoon I and II.

\begin{tabular}{cc|cc}
\hline \multicolumn{2}{c|}{ Latitude/longitude for the PJ index } & \multicolumn{2}{|c}{ PJ index } \\
\hline northern point & southern point & Monsoon I (79 cases) & Monsoon II (55 cases) \\
$30^{\circ} \mathrm{N}, 130^{\circ} \mathrm{E}$ & $15^{\circ} \mathrm{N}, 120^{\circ} \mathrm{E}$ & $-226.34 \mathrm{~m}^{2} \mathrm{~s}^{-1}$ & $291.65 \mathrm{~m}^{2} \mathrm{~s}^{-1}$ \\
\hline
\end{tabular}
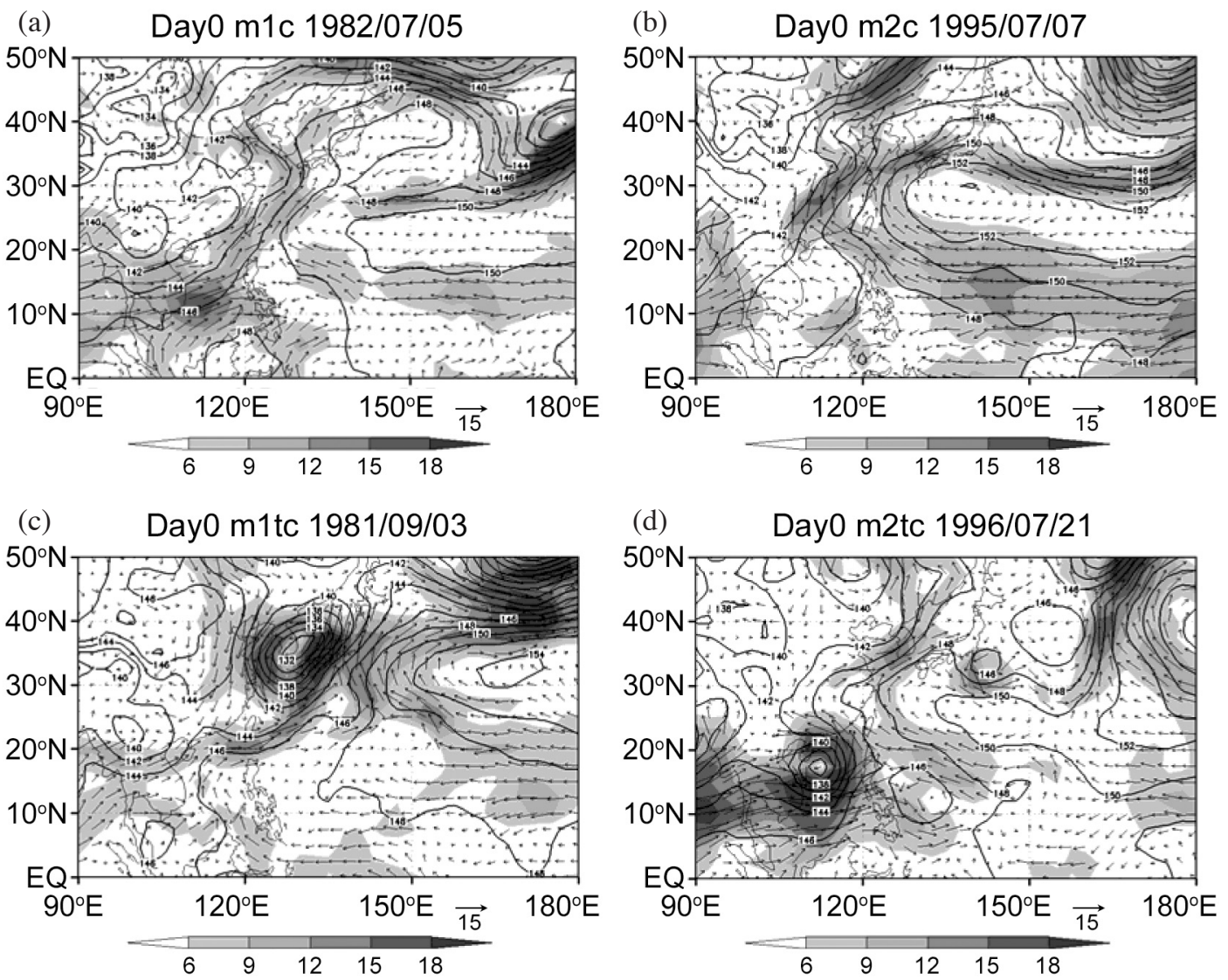

Fig. 10. Typical patterns of $850 \mathrm{hPa}$ geopotential and wind vectors for Monsoon I, II, I-TC, and II-TC cases at Day0 [(a), (b), (c), and (d), respectively]. The shaded areas stand for wind speed $\left(\mathrm{m} \mathrm{s}^{-1}\right)$ greater than $6 \mathrm{~m} \mathrm{~s}^{-1}$. The interval for geopotential is $1(\times 100) \mathrm{m}^{2} \mathrm{~s}^{-1}$. 

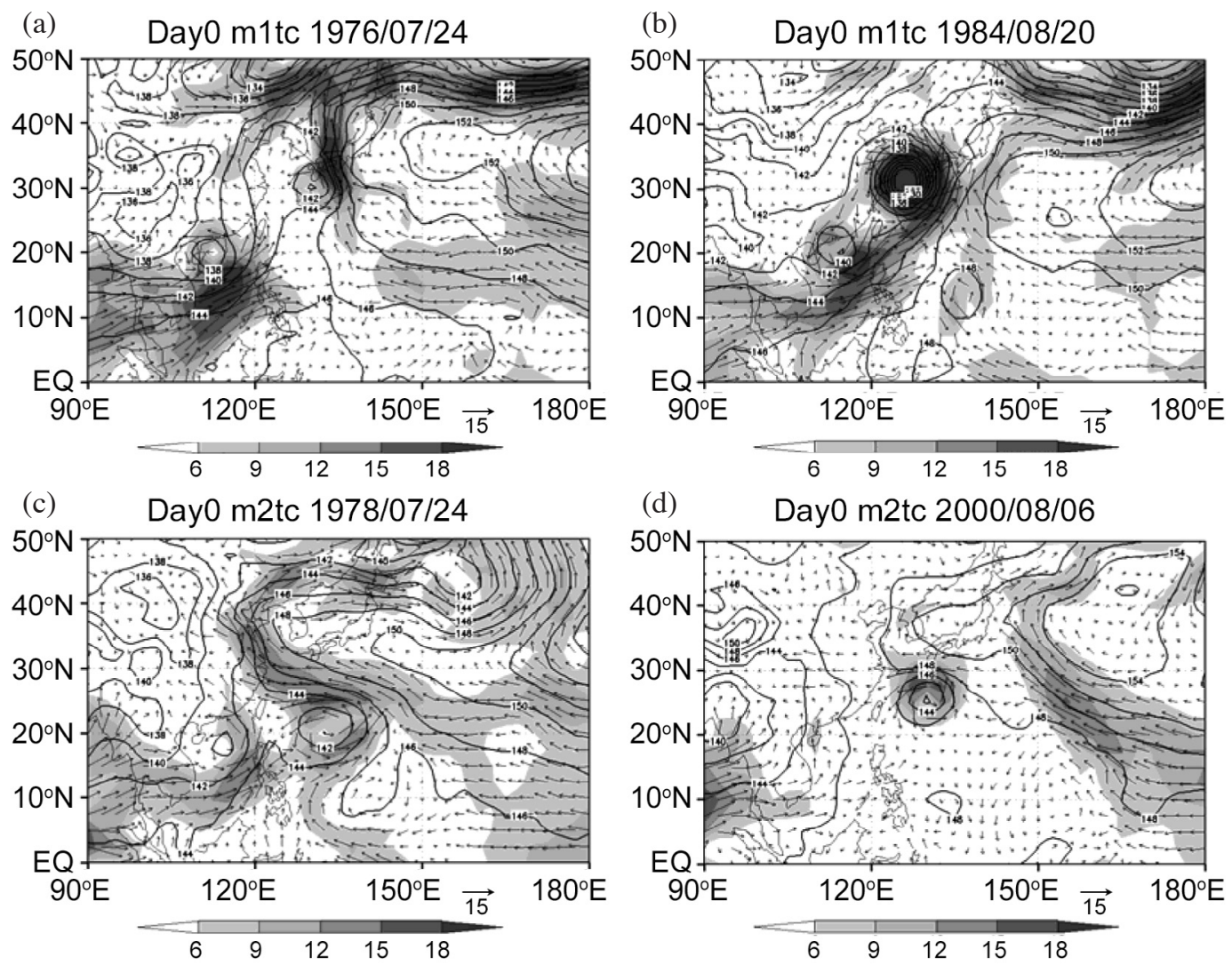

Fig. 11. Maps of $850 \mathrm{hPa}$ geopotential and wind vectors for selected TC cases at Day0 [(a) and (b) for Monsoon I-TC, and (c) and (d) for Monsoon II-TC]. Also shown are the areas for the maximum wind speed $\left(\mathrm{m} \mathrm{s}^{-1}\right)$. The interval for geopotential is $1(\times 100) \mathrm{m}^{2} \mathrm{~s}^{-1}$.
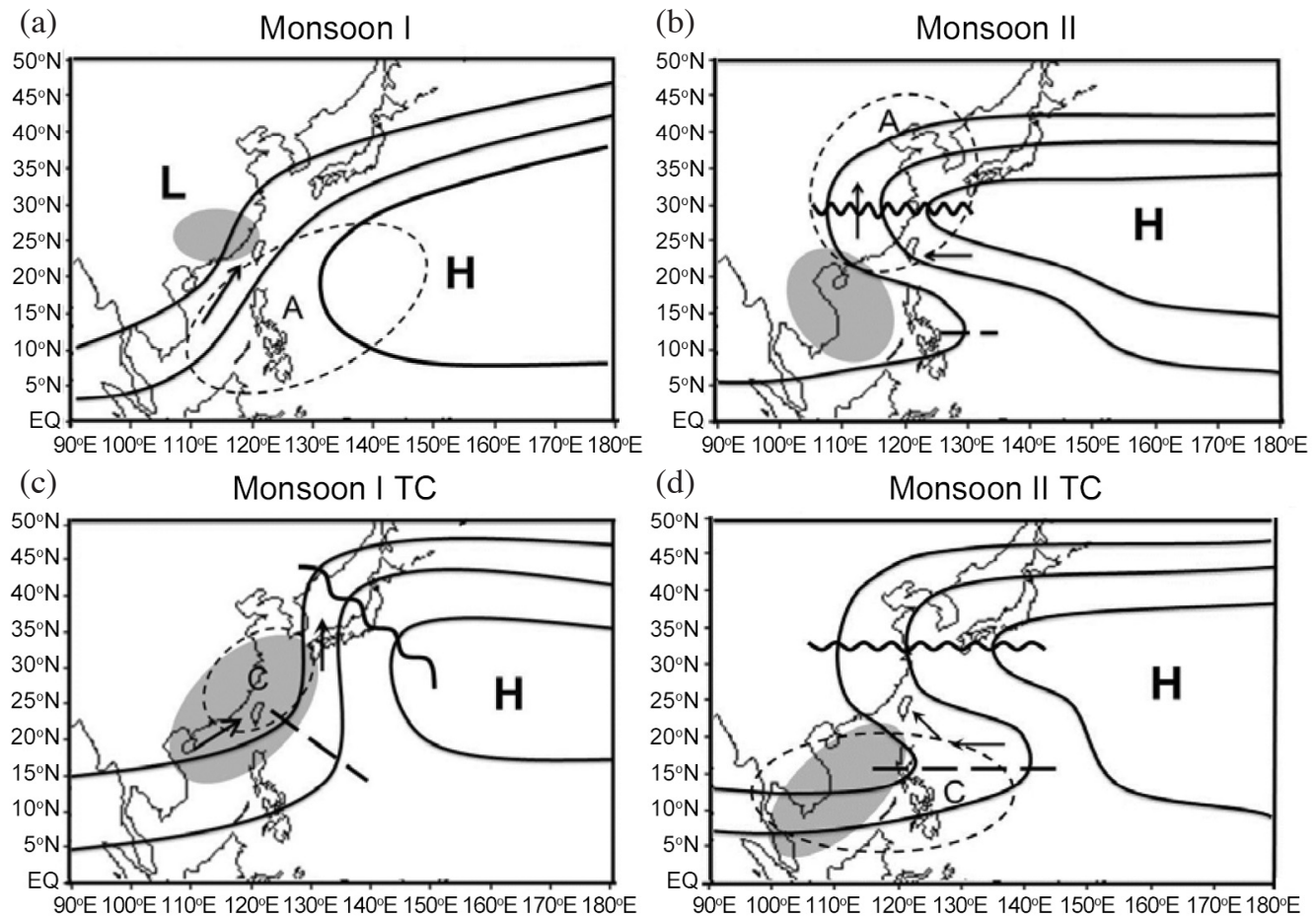

Fig. 12. Schematic diagrams for $850 \mathrm{hPa}$ geopotential at Day0 for Monsoon I, II, I-TC, and II-TC [(a), (b), (c), and (d), respectively]. The solid lines stand for the contours of the geopotential and the highs and lows are denoted as $\mathrm{H}$ and L. The ridges and troughs are marked by thick wavy and dashed lines, respectively. The arrows represent the areas of strong wind. The areas surrounded by thin dashed lines are the anomalous cyclonic (C) and anticyclonic (A) areas. The shaded areas are the anomalous convective areas. 
sure gradient between the monsoon trough and subtropical ridge. The anomalous fields of Monsoon I also support the enhancement of the southwesterly flow. This Monsoon I pattern is similar to the climatological mean structure of early summer as found in Hsu (2005). However, the circulation pattern and anomalous fields of Monsoon I-TC exhibit a deeper trough from southwestern to eastern China and merge with a closed cyclonic circulation over the East China Sea. The enhanced southwesterly flow over the southern flank of this trough drives the moisture to support the deepening of the trough as well as the TCs.

The Monsoon II circulation pattern exhibits a monsoon trough extending from northern Vietnam to east of the Philippines and a strong ridge which is located to the north of Taiwan stretching westward from the subtropical high and the southern flank of the ridge drives the southeasterly flow to Taiwan. The western portion of this ridge coincides with the anomalous anticyclone. The circulation pattern of Monsoon II is similar to the PJ pattern (Nitta 1987) with a wavy meridional structure. Nitta (1987) proposes the possibility of Rossby waves generated by tropical heating; these wave trains emanate from the Philippines to North America. Kosaka and Nakamura (2010) claim that the PJ pattern can not only be generated by tropical heating but also enhance the convective activity near the Philippines. A modified PJ index suggests that during the July-September season, the meridional out-of-phase patterns of Monsoon I (and I-TC) and Monsoon II (and II-TC) tend to occur alternatively near Taiwan. However, the rainfall of Monsoon II is less due to the suppression of convection by the western North Pacific high. Lin and Wang (2002) also find a similar pattern during their Pentad 46 - 47. On the other hand, the Monsoon II-TC pattern, though less significant, yields a structure with a deeper monsoon trough located south of the subtropical ridge. This trough and the anomalous cyclone are favorable for TCs to form and develop (Chang et al. 1996) so southern Taiwan can be influenced by these systems. However, there also exist several cases that the TCs located east to Taiwan can have some impacts on southern Taiwan. The wide variety of Monsoon II-TC cases is the reason for this pattern to be less significant.

Acknowledgements The authors thank those two anonymous reviewers for providing important physical interpretation of the monsoon pattern and are grateful for the Data Bank for providing the data. This study was supported by the National Science Council, Taiwan under Grant NSC 982111-M-017-001

\section{REFERENCES}

Chang, C.-P., J. M. Chen, P. A. Harr, and L. E. Carr, 1996: Northwestward-propagating wave patterns over the tropical western North Pacific during summer. Mon.
Weather Rev., 124, 2245-2266, doi: 10.1175/1520-04 93(1996) $124<2245$ :NPWPOT>2.0.CO;2. [Link]

Chen, J. M. and H. L. Fan, 2003: Interannual variability of the South China Sea summer rainfall and typhoon invading Taiwan. Atmos. Sci., 31, 221-238. (in Chinese)

Chen, J. M., T. Li, and C. F. Shih, 2010: Tropical cycloneand monsoon-induced rainfall variability in Taiwan. J. Climate, 23, 4107-4120, doi: 10.1175/2010JCLI33 55.1. [Link]

Choi, K. S., C. C. Wu, and E. J. Cha, 2010: Change of tropical cyclone activity by Pacific-Japan teleconnection pattern in the western North Pacific. J. Geophys. Res., 115, D19114, doi: 10.1029/2010JD013866. [Link]

Chou, C., L. F. Huang, L. Tseng, J. Y. Tu, and P. H. Tan, 2009: Annual cycle of rainfall in the western North Pacific and East Asian sector. J. Climate, 22, 2073-2094, doi: 10.1175/2008JCLI2538.1. [Link]

Holland, G. J., 1995: Scale interaction in the western Pacific monsoon. Meteorol. Atmos. Phys., 56, 57-79, doi: 10.1007/BF01022521. [Link]

Hoskins, B. J. and D. J. Karoly, 1981: The steady linear response of a spherical atmosphere to thermal and orographic forcing. J. Atmos. Sci., 38, 1179-1196, doi: 10.1175/1520-0469(1981)038<1179:TSLROA > 2.0. $\mathrm{CO} ; 2$. [Link]

Hsu, H. H., 2005: Intraseasonal variability in the atmosphere-ocean climate system: East Asian monsoon. In: Lau, W. K.-M. and D. E. Waliser (Authors), Intraseasonal Variability in the Atmosphere-Ocean Climate System, Springer Praxis Books, Environmental Sciences, 65-98.

Hsu, H. H. and C. H. Weng, 2001: Northwestward propagation of the intraseasonal oscillation in the western North Pacific during the boreal summer: structure and mechanism. J. Climate, 14, 3834-3850, doi: 10.1175/ 1520-0442(2001)014<3834:NPOTIO>2.0.CO;2. [Link]

Hsu, H. H. and S. M. Lin, 2007: Asymmetry of the tripole rainfall pattern during the East Asian summer. J. Climate, 20, 4443-4458, doi: 10.1175/JCLI4246.1. [Link]

Ko, K. C. and H. H. Hsu, 2006: Sub-monthly circulation features associated with tropical cyclone tracks over the East Asian monsoon area during July-August season. J. Meteorol. Soc. Jpn., 84, 871-889, doi: 10.2151/ jmsj.84.871. [Link]

Ko, K. C. and H. H. Hsu, 2009: ISO Modulation on the submonthly wave pattern and recurving tropical cyclones in the tropical western North Pacific. J. Climate, 22, 582-599, doi: 10.1175/2008JCLI2282.1. [Link]

Kosaka, Y. and H. Nakamura, 2010: Mechanisms of meridional teleconnection observed between a summer monsoon system and a subtropical anticyclone. Part I: The Pacific-Japan pattern. J. Climate, 23, 5085-5108, doi: 10.1175/2010JCLI3413.1. [Link] 
Lau, K. H., and N. C. Lau, 1990: Observed structure and propagation characteristics of tropical summertime synoptic scale disturbances. Mon. Weather Rev., 118, 1888-1913, doi: 10.1175/1520-0493(1990)118<1888: OSAPCO $>2.0 . \mathrm{CO} ; 2$. [Link]

Lin, H. and B. Wang, 2002: The time - Space structure of the Asian - Pacific summer monsoon: A fast annual cycle view. J. Climate, 15, 2001-2019, doi: 10.1175/15200442(2002)015<2001:TTSSOT>2.0.CO;2. [Link]

Matsumoto, J., 1992: The seasonal changes in Asian and Australian monsoon regions. J. Meteorol. Soc. Jpn., 70, 257-273.

Nitta, T., 1987: Convective activities in the tropical western Pacific and their impact on the northern hemisphere summer circulation. J. Meteorol. Soc. Jpn., 65, 373390.

Uppala, S. M., P. W. KÅllberg, A. J. Simmons, U. Andrae,
V. Da Costa Bechtold, M. Fiorino, J. K. Gibson, J. Haseler, A. Hernandez, G. A. Kelly, X. Li, K. Onogi, S. Saarinen, N. Sokka, R. P. Allan, E. Andersson, K. Arpe, M. A. Balmaseda, A. C. M. Beljaars, L. Van De Berg, J. Bidlot, N. Bormann, S. Caires, F. Chevallier, A. Dethof, M. Dragosavac, M. Fisher, M. Fuentes, S. Hagemann, E. Hólm, B. J. Hoskins, L. Isaksen, P. A. E. M. Janssen, R. Jenne, A. P. Mcnally, J.-F. Mahfouf, J.J. Morcrette, N. A. Rayner, R. W. Saunders, P. Simon, A. Sterl, K. E. Trenberth, A. Untch, D. Vasiljevic, P. Viterbo, and J. Woollen, 2005: The ERA-40 re-analysis. Q. J. R. Meteorol. Soc., 131, 2961-3012, doi: 10.1256/qj.04.176. [Link]

Wang, B. and H. Lin, 2002: Rainy season of the Asian - Pacific summer monsoon. J. Climate, 15, 386-398, doi: 10.1175/1520-0442(2002)015<0386:RSOTAP >2.0. CO;2. [Link] 